\section{JURNAL EKONOMI EFEKTIF}

ISSN : $2622-8882$, E-ISSN : 2622-9935

Jurnal Ekonomi Efektif, Vol. 3, No. 2, Januari 2021 @Prodi Manajemen Fakultas Ekonomi Universitas Pamulang

\title{
PENGARUH PROSES BELAJAR MENGAJAR, MOTIVASI BELAJAR DAN LINGKUNGAN BELAJAR KAMPUS TERHADAP PRESTASI BELAJAR
}

\author{
Regi Frandwi Arisandi \\ Universitas Pamulang, Tangerang Selatan, Banten, Indonesia \\ dosen02567@unpam.ac.id
}

Manuskrip: Okt-2020; Ditinjau: Nov-2020; Diterima: Nov-2020; Online: Jan-2021; Diterbitkan: Jan-2021

\begin{abstract}
ABSTRAK
Penelitian ini bertujuan untuk mengetahui pengaruh proses belajar mengajar, motivasi belajar dan lingkungan belajar kampus terhadap prestasi belajar mahasiswa S.1 Teknik Kimia Universitas Pamulang. Penelitian ini adalah penelitian kuantitatif dengan metode deskriptif kuantitatif. Populasi dalam penelitian ini adalah mahasiswa S1 Teknik Kimia Universitas Pamulang pada tahun akademik 2017/2018 sebanyak 472 orang dengan sampel sebanyak 217 orang responden mahasiswa. Instrumen data yang digunakan adalah kuesioner dengan skala Likert. Pengujian hipotesis menggunakan uji parsial dan uji simultan dengan menggunakan program SPSS (Statistical Package for Social Sciences) versi 22. Hasil penelitian terdapat pengaruh positif dan signifikan proses belajar mengajar, motivasi belajar dan lingkungan belajar kampus secara simultan (bersama-sama) terhadap prestasi belajar dengan nilai nilai $\mathrm{F}$ hitung > F tabel $(53,127>2,647)$.
\end{abstract}

\section{Kata Kunci : Proses Belajar Mengajar, Motivasi Belajar, Lingkungan Belajar Kampus dan Prestasi Belajar}

\begin{abstract}
This study aims to determine the effect of the teaching and learning process, learning motivation and campus learning environment on student achievement of S.1 Chemical Engineering Pamulang University. This research is a quantitative research with quantitative descriptive methods. The population in this study were 472 students of S1 Chemical Engineering at Pamulang University in the 2017/2018 academic year with a sample of 217 student respondents. The data instrument used was a questionnaire with a Likert scale. Hypothesis testing uses partial test and simultaneous test using the SPSS (Statistical Package for Social Sciences) program version 22. The results of the study have a positive and significant influence on the teaching and learning process, learning motivation and the campus learning environment simultaneously (together) on learning achievement with $F$ value count $>F$ table $(53,127>2,647)$.
\end{abstract}

Keywords: Teaching and Learning Process, Learning Motivation, Campus Learning Environment and Learning Achievement 


\section{PENDAHULUAN}

\section{A. Latar Belakang Masalah}

Pendidikan merupakan cara yang tepat untuk membentuk sumber daya manusia yang berkualitas. Melalui pendidikan, manusia mendapatkan pengetahuan, keterampilan, nilai dan sikap. Perguruan tinggi merupakan salah satu tempat yang dinilai bagus untuk meningkatkan mutu pendidikan. Kebijakan peningkatakan mutu pendidikan diarahkan pada pencapaian mutu pendidikan yang mengacu pada standar nasional pendidikan yang berupa standar proses, standar kompetensi lulusan, standar pendidik dan tenaga kependidikan, standar sarana dan prasarana, standar pengelolaan, standar pembiayaan dan standar penilaian pendidikan. Peningkatan mutu juga mencakup hasil keluaran (output), proses dan masukkan (input). Jadi, saat ini perlu ditekankan pentingnya pengembangan kualitas sumber daya manusia untuk mencapai keunggulan bangsa dalam persaingan global. Karenanya, peran institusi pendidikan sebagai sebuah organisasi yang mengolah input sumber daya manusia menjadi sumber daya manusia yang berkualitas sangat penting.

Peningkatan kualitas mutu pendidikan dan pengembangan proses belajar mengajar merupakan masalah yang perlu diperhatikan perguruan tinggi. Perbedaan tingkat serap antara mahasiswa satu dengan yang lainnya terhadap materi pembelajaran menuntut seorang dosen melakukan cara yang tepat dalam pembelajaran. sehingga tidak sekedar menyajikan materi, tetapi uga perlu menggunakan metode yang sesuai, disukai dan mempermudah pemahaman siswa.

Proses belajar mengajar dalam perguruan tinggi secara umum melibatkan empat buah komponen utama, yaitu: dosen, mahasiswa, lingkungan belajar dan materi pelajaran. Proses interaksi antara dosen dan mahasiswa sangat penting sekali dalam kelangsungan proses belajar mengajar, karena dalam proses belajar mengajar dosen menyampaikan suatu pesan berupa pengetahuan, keterampilan, sikap dan etika kepada para mahasiswa. Dari hasil pengamatan pada Program Studi Teknik Kimia Universitas Pamulang, interaksi yang terjadi antara dosen dan mahasiswa pada proses belajar mengajar ditemukan berbagai macam kondisi yang dapat menghambat proses interaksi tersebut. Beberapa hambatan tersebut antara lain, sebagian mahasiswa kurang percaya diri untuk berinteraksi dengan dosen ketika proses belajar mengajar berlangsung, sebagian terkesan takut memberikan pertanyaan maupun tanggapan kepada dosen. Kebanyakan mahasiswa hanya menjadi pendengar dan pasif saja. Sebagian mahasiswa kurang memperhatikan penjelasan dari dosen dan lebih asyik mengobrol dengan mahasiswa lain ketika kegiatan belajar mengajar berlangsung. Dosen belum maksimal dalam mengelola kelas dan menciptakan kondisi kelas yang kondusif. Hal ini mengakibatkan terhambatnya proses interaksi ketika proses belajar mengajar berlangsung. Sehingga proses belajar mengajar menjadi tidak efektif.

Motivasi belajar merupakan salah satu faktor yang turut menentukan keefektifan dalam pembelajaran. Menurut Syamsu Yusuf (2009: 23) Motivasi belajar dapat timbul karena factor internal dan eksternal. Faktor internal yang mempengaruhi motivasi belajar yaitu: (1) Faktor Fisik meliputi: nutrisi (gizi), kesehatan, dan fungsi-fungsi fisik (terutama panca indera), (2) Faktor Psikologis, yaitu berhubungan dengan aspek-aspek yang mendorong atau menghambat aktivitas belajar pada siswa. Faktor eksternal (yang berasal dari lingkungan) yang mempengaruhi motivasi belajar meliputi: (1) Faktor NonSosial meliputi keadaan udara (cuaca panas atau dingin), waktu (pagi, siang, malam), tempat (sepi, bising, atau kualitas tempat belajar), sarana dan prasarana atau fasiltas belajar (2) Faktor Sosial, merupakan faktor manusia (guru, konselor dan orang tua). Berdasarkan hasil pengamatan pada mahasiswa Program Studi Teknik Kimia Universitas 
Pamulang, motivasi belajar beberapa mahasiswa masih rendah disebabkan beberapa mahasiswa merasa bosan dengan cara mengajar dosen dan diajar oleh dosen yang sama dalam beberapa semester, fasilitas belajar seperti: peralatan laboratorium belum lengkap, ketersediaan buku teknik kimia diperpustakaan masih sedikit, penggunaan program kuliah E-Learning untuk mahasiswa dinilai sulit terutama untuk mata kuliah hitungan dan masalah koneksi internet yang lambat. Dari segi disiplin waktu, beberapa mahasiswa sering telat bila waktu perkuliahan pagi pukul 07.30 WIB. Sehingga mempengaruhi prestasi belajar mahasiswa. Berikut tabel Indeks Prestasi Kumulatif (IPK) mahasiswa lulusan per tahun Program Studi S.1 Teknik Kimia Universitas Pamulang untuk 7 tahun terakhir pada Tahun Ajaran 2010/2011 sampai dengan 2016/2017.

Tabel 1. Indeks Prestasi Kumulatif (IPK) Mahsiswa Lulusan /Tahun

\begin{tabular}{|c|c|c|c|c|}
\hline \multirow{2}{*}{ No. } & \multirow{2}{*}{ Tahun } & \multicolumn{3}{|c|}{ IPK Mahasiswa Lulusan / Tahun } \\
\cline { 3 - 5 } & & Terendah & Tertinggi & Rata-Rata \\
\hline 1 & $2010 / 2011$ & 2,71 & 3,31 & 3,01 \\
\hline 2 & $2011 / 2012$ & 3,16 & 3,75 & 3,42 \\
\hline 3 & $2012 / 2013$ & 2,74 & 3,42 & 3,26 \\
\hline 4 & $2013 / 2014$ & 3,02 & 3,23 & 3,08 \\
\hline 5 & $2014 / 2015$ & 3,00 & 3,62 & 3,31 \\
\hline 6 & $2015 / 2016$ & 2,87 & 3,72 & 3,26 \\
\hline 7 & $2016 / 2017$ & 2,91 & 3,82 & 3,34 \\
\hline
\end{tabular}

Sumber: Bagian Tata Usaha Program Studi Teknik Kimia (2018)

Dari uraian yang telah dikemukakan diatas, maka peneliti tertarik untuk meneliti masalah ini ke dalam tesis dengan judul "Pengaruh Proses Belajar Mengajar, Motivasi Belajar dan Lingkungan Belajar Kampus terhadap Prestasi Belajar Mahasiswa S.1 Teknik Kimia Universitas Pamulang”.

\section{B. Perumusan Masalah}

Dari batasan masalah yang telah disampaikan maka hal tersebut dijadikan sebagai ruang lingkup dalam penelitian yang dilakukan peneliti, lebih lanjut batasan-batasan tersebut kemudian dijadikan dasar guna merumuskan masalah. Adapun rumusan masalah tersebut adalah sebagai berikut:

1. Seberapa besar pengaruh proses belajar mengajar terhadap prestasi belajar mahasiswa S.1 Teknik Kimia Universitas Pamulang?

2. Seberapa besar pengaruh motivasi belajar terhadap prestasi belajar mahasiswa S.1 Teknik Kimia Universitas Pamulang?

3. Seberapa besar pengaruh lingkungan belajar terhadap prestasi belajar mahasiswa S.1 Teknik Kimia Universitas Pamulang?

4. Seberapa besar pengaruh proses belajar mengajar, motivasi belajar, dan lingkungan belajar kampus secara simultan terhadap prestasi belajar mahasiswa S.1 Teknik Kimia Universitas Pamulang?

\section{Tujuan Penelitian}

Tujuan peneliti melakukan penelitian ini yaitu:

1. Untuk mengetahui seberapa besar pengaruh proses belajar mengajar terhadap prestasi belajar mahasiswa S.1 Teknik Kimia Universitas Pamulang.

2. Untuk mengetahui seberapa besar pengaruh motivasi belajar terhadap prestasi belajar 
mahasiswa S.1 Teknik Kimia Universitas Pamulang.

3. Untuk mengetahui seberapa besar pengaruh lingkungan belajar terhadap prestasi belajar mahasiswa S.1 Teknik Kimia Universitas Pamulang.

4. Untuk mengetahui seberapa besar pengaruh proses belajar mengajar, motivasi belajar, dan lingkungan belajar kampus secara simultan terhadap prestasi belajar mahasiswa S.1 Teknik Kimia Universitas Pamulang.

\section{METODE PENELITIAN}

\section{Populasi}

Populasi dalam penelitian ini adalah mahasiswa S1 Teknik Kimia Universitas Pamulang pada tahun akademik 2017/2018., sebanyak 472 orang.

\section{Sampel}

Teknik sampling yang digunakan adalah teknik Proporsional Random Sampling, yakni pemilihan sampel yang dilakukan secara acak dengan cara dihitung secara proporsional. Didalam penelitian ini sampel diambil secara acak, dan sesuai dengan rumus ukuran sampel diatas. Adapun jumlah sampel yang diambil adalah sebagai berikut:

$$
\mathrm{n}=\frac{\mathrm{N}}{\mathrm{N}(\mathrm{e})^{2}+1}=\frac{472}{472(0,05)^{2}+1}=216,513 \text { dibulatkan } 217
$$

Jumlah sampel penelitian sebanyak 217 responden

\section{Jenis Penelitian}

Jenis penelitian yang dipakai adalah asosiatif, dimana tujuannya adalah untuk mengetahui mencari keterhubungan antara variabel $\mathrm{x}$ dan variabel $\mathrm{y}$

\section{Metode Analisis Data}

Dalam menganalisis data digunakan uji instrumen, uji asumsi klasik, regresi, koefisien determinasi dan uji hipotesis.

\section{HASIL PENELITIAN DAN PEMBAHASAN \\ 1. Uji Regresi Linear Berganda}

Regresi linier berganda digunakan untuk menganalisis pengaruh dari berbagai variabel bebas terhadap satu variabel terikat. Dalam penelitian ini terdapat beberapa variabel bebas yaitu proses belajar mengajar $\left(\mathrm{X}_{1}\right)$, motivasi belajar $\left(\mathrm{X}_{2}\right)$ dan lingkungan belajar kampus $\left(\mathrm{X}_{3}\right)$ berpengaruh terhadap variabel terikat yaitu prestasi belajar (Y). Adapun hasil uji regresi linier berganda dalam penelitian ini sebagai berikut:

Tabel 2. Hasil Uji Regresi Linier Berganda Variabel $\mathrm{X}_{1}, \mathrm{X}_{2}$ dan $\mathrm{X}_{3}$ terhadap $\mathrm{Y}$

\begin{tabular}{|c|c|c|c|c|c|c|}
\hline \multicolumn{7}{|c|}{ Coefficients $^{a}$} \\
\hline \multirow[b]{2}{*}{ Model } & & \multicolumn{2}{|c|}{$\begin{array}{l}\text { Unstandardized } \\
\text { Coefficients }\end{array}$} & \multirow{2}{*}{$\begin{array}{c}\begin{array}{c}\text { Standardized } \\
\text { Coefficients }\end{array} \\
\text { Beta }\end{array}$} & \multirow[b]{2}{*}{$\mathrm{t}$} & \multirow[b]{2}{*}{ Sig. } \\
\hline & & B & $\begin{array}{l}\text { Std. } \\
\text { Error }\end{array}$ & & & \\
\hline 1 & (Constant) & 10.310 & 2.075 & & 4.968 & .000 \\
\hline & Proses Belajar Mengajar (X1) & .285 & .149 & .275 & 1.915 & .057 \\
\hline & Motivasi Belajar (X2) & .178 & .158 & .167 & 1.126 & .261 \\
\hline & Lingkungan Belajar Kampus (X3) & .283 & .077 & .270 & 3.650 & .000 \\
\hline
\end{tabular}

a. Dependent Variable: Prestasi Belajar $(\mathrm{Y})$

Sumber: Data primer, diolah peneliti dengan SPSS versi 22 (2018)

Berdasarkan tabel 2. hasil uji regresi linier berganda variabel $\mathrm{X}_{1}, \mathrm{X}_{2}$ dan $\mathrm{X}_{3}$ terhadap $\mathrm{Y}$, maka dapat diperoleh bentuk persamaan regresi $\mathrm{Y}=10,310+0,285 \mathrm{X}_{1}+$ $0,178 \mathrm{X}_{2}+0,283 \mathrm{X}_{3}$. 


\section{Uji Koefisien Determinasi $\left(\mathbf{R}^{\mathbf{2}}\right)$}

Hasil Uji Koefisien Determinasi Variabel proses belajar mengajar $\left(\mathrm{X}_{1}\right)$, motivasi belajar $\left(\mathrm{X}_{2}\right)$ dan lingkungan belajar kampus $\left(\mathrm{X}_{2}\right)$ terhadap Prestasi Belajar $(\mathrm{Y})$.

Tabel 3. Hasil Uji Koefisien Determinasi Variabel $X_{1}, X_{2}$ dan $X_{3}$ terhadap $Y$ Model Summary

\begin{tabular}{|l|l|r|r|r|}
\hline Model & $\mathrm{R}$ & R Square & Adjusted R Square & Std. Error of the Estimate \\
\hline 1 & $.654^{\mathrm{a}}$ & .428 & .420 & 2.627 \\
\hline
\end{tabular}

a. Predictors: (Constant), Lingkungan Belajar Kampus, Proses Belajar Mengajar, Motivasi Belajar b. Dependent Variable: Prestasi Belajar

Sumber: Data primer, diolah peneliti dengan SPSS versi 22 (2018)

Berdasarkan tabel 3. hasil uji koefisien determinasi proses belajar mengajar $\left(\mathrm{X}_{1}\right)$, motivasi belajar $\left(\mathrm{X}_{2}\right)$ dan lingkungan belajar kampus $\left(\mathrm{X}_{3}\right)$ terhadap prestasi belajar $(\mathrm{Y})$, diperoleh nilai koefisien determinasi sebesar 0,428, maka dapat disimpulkan bahwa proses belajar mengajar $\left(\mathrm{X}_{1}\right)$, motivasi belajar $\left(\mathrm{X}_{2}\right)$ dan lingkungan belajar kampus $\left(\mathrm{X}_{3}\right)$ terhadap prestasi belajar (Y) sebesar $42,8 \%$ sedangkan sisanya $57,2 \%$ dipengaruhi oleh faktor-faktor lain.

\section{Uji Hipotesis}

Adapun hasil uji Uji parsial (Uji t) dalam penelitian ini sebagai berikut: Tabel 4. Hasil Uji Simultan (Uji F) Variabel $X_{1}, X_{2}$ dan $X_{3}$ terhadap Y ANOVA ${ }^{a}$

\begin{tabular}{|ll|r|r|r|r|r|}
\hline Model & & Sum of Squares & Df & Mean Square & F & Sig. \\
\hline 1 & Regression & 1099.692 & 3 & 366.564 & 53.127 & $.000^{\mathrm{b}}$ \\
& Residual & 1469.653 & 213 & 6.900 & & \\
& Total & 2569.346 & 216 & & & \\
\hline
\end{tabular}

a. Dependent Variable: Prestasi Belajar

b. Predictors: (Constant), Lingkungan Belajar Kampus, Proses Belajar Mengajar, Motivasi Belajar

Sumber: Data primer, diolah peneliti dengan SPSS versi 22 (2018)

Berdasarkan tabel 4. hasil uji simultan (Uji F) variabel $\mathrm{X}_{1}, \mathrm{X}_{2}$ dan $\mathrm{X}_{3}$ terhadap $\mathrm{Y}$ dapat disimpulkan bahwa nilai $F_{\text {hitung }}>F_{\text {tabel }}(53,127>2,647)$ dan nilai signifikansi variabel $X_{1}, X_{2}$ dan $X_{3}$ sebesar $0,000<0,05$, terdapat pengaruh positif dan signifikan proses belajar mengajar $\left(\mathrm{X}_{1}\right)$, motivasi belajar $\left(\mathrm{X}_{2}\right)$ dan lingkungan belajar kampus $\left(\mathrm{X}_{3}\right)$ secara simultan (bersama-sama) terhadap prestasi belajar (Y). sehingga dapat disimpulkan Ho4 ditolak dan Ha4 diterima.

\section{PEMBAHASAN HASIL PENELITIAN}

Setelah melakukan hasil uji secara statistik mulai dari uji kualitas data, uji asumsi klasik, uji regresi, uji koefisien determinasi maupun uji hipotesis. Untuk mempermudah pembahasan, akan dijelaskan pengaruh dari masing-masing variabel independen yang meliputi; proses belajar mengajar $\left(\mathrm{X}_{1}\right)$, motivasi belajar $\left(\mathrm{X}_{2}\right)$ dan lingkungan belajar kampus $\left(\mathrm{X}_{3}\right)$ serta variabel dependen prestasi belajar $(\mathrm{Y})$. sebagai berikut:

1. Pengaruh Proses Belajar Mengajar $\left(\mathrm{X}_{1}\right)$ terhadap Prestasi Belajar (Y)

Berdasarkan hasil olah data uji statistik yaitu dengan uji parsial (uji t), variabel proses belajar mengajar $\left(\mathrm{X}_{1}\right)$ terhadap prestasi belajar $(\mathrm{Y})$, dapat disimpulkan bahwa nilai $\mathrm{t}$ hitung $>\mathrm{t}$ tabel $(11,464>1,971)$, artinya terdapat pengaruh yang positif antara proses belajar mengajar $\left(\mathrm{X}_{1}\right)$ secara parsial (sendiri-sendiri) terhadap prestasi belajar $(\mathrm{Y})$.

Dalam uji signifikansi, nilai signifikansi variabel proses belajar mengajar $\left(\mathrm{X}_{1}\right)$ sebesar $0,000<0,05$, artinya terjadi pengaruh yang signifikan antara proses belajar 
mengajar $\left(\mathrm{X}_{1}\right)$ secara parsial (sendiri-sendiri) terhadap prestasi belajar $(\mathrm{Y})$. sehingga dapat disimpulkan Ho1 ditolak dan Ha1 diterima (terdapat pengaruh positif dan signifikan proses belajar mengajar terhadap prestasi belajar).

2. Pengaruh Motivasi Belajar $\left(\mathrm{X}_{2}\right)$ terhadap Prestasi Belajar (Y)

Berdasarkan hasil olah data uji statistik yaitu dengan uji parsial (uji t) variabel motivasi belajar $\left(\mathrm{X}_{2}\right)$ terhadap prestasi belajar (Y), dapat disimpulkan bahwa nilai $\mathrm{t}$ hitung $>\mathrm{t}$ tabel $(11,441>1,971)$, artinya terdapat pengaruh yang positif antara motivasi belajar $\left(\mathrm{X}_{2}\right)$ secara parsial (sendiri-sendiri) terhadap prestasi belajar $(\mathrm{Y})$.

Dalam uji signifikansi, nilai signifikansi variabel motivasi belajar $\left(\mathrm{X}_{2}\right)$ sebesar $0,000<0,05$, artinya terjadi pengaruh yang signifikan antara motivasi belajar $\left(\mathrm{X}_{2}\right)$ secara parsial terhadap prestasi belajar (Y). sehingga dapat disimpulkan Ho2 ditolak dan Ha2 diterima (terdapat pengaruh positif dan signifikan motivasi belajar terhadap prestasi belajar).

3. Pengaruh Lingkungan Belajar Kampus $\left(\mathrm{X}_{3}\right)$ terhadap Prestasi Belajar (Y)

Berdasarkan hasil olah data uji statistik yaitu dengan uji parsial (uji t) variabel lingkungan belajar kampus $\left(\mathrm{X}_{3}\right)$ terhadap prestasi belajar $(\mathrm{Y})$ dapat disimpulkan bahwa nilai $\mathrm{t}$ hitung $>\mathrm{t}$ tabel $(10,365>1,971)$, artinya terdapat pengaruh yang positif antara lingkungan belajar kampus $\left(\mathrm{X}_{3}\right)$ secara parsial (sendiri-sendiri) terhadap prestasi belajar (Y).

Dalam uji signifikansi, nilai signifikansi variabel lingkungan belajar kampus $\left(\mathrm{X}_{3}\right)$ sebesar $0,000<0,05$, artinya terjadi pengaruh yang signifikan antara lingkungan belajar kampus $\left(\mathrm{X}_{3}\right)$ secara parsial terhadap prestasi belajar $(\mathrm{Y})$. sehingga dapat disimpulkan Ho3 ditolak dan Ha3 diterima (terdapat pengaruh positif dan signifikan lingkungan belajar kampus terhadap prestasi belajar).

4. Pengaruh Proses Belajar Mengajar $\left(X_{1}\right)$, Motivasi Belajar $\left(X_{2}\right)$ dan Lingkungan Belajar Kampus $\left(\mathrm{X}_{3}\right)$ terhadap Prestasi Belajar (Y)

Berdasarkan hasil olah data uji statistik yaitu dengan uji simultan (Uji F) variabel proses belajar mengajar $\left(\mathrm{X}_{1}\right)$, motivasi belajar $\left(\mathrm{X}_{2}\right)$ dan lingkungan belajar kampus $\left(\mathrm{X}_{3}\right)$ terhadap Prestasi Belajar (Y), dapat disimpulkan bahwa nilai $\mathrm{F}$ hitung $>\mathrm{F}_{\text {tabel }}(53,127>$ 2,647 ), artinya terdapat pengaruh yang positif antara proses belajar mengajar, motivasi belajar dan lingkungan belajar kampus secara simultan (bersama-sama) terhadap prestasi belajar (Y).

Dalam uji signifikansi, nilai signifikansi variabel variabel proses belajar mengajar $\left(X_{1}\right)$, motivasi belajar $\left(X_{2}\right)$ dan lingkungan belajar kampus $\left(X_{3}\right)$ sebesar $0,000<0,05$, menandakan bahwa terjadi pengaruh yang signifikan. Sehingga dapat disimpulkan Ho4 ditolak dan Ha4 diterima, artinya terdapat pengaruh positif dan signifikan proses belajar mengajar, motivasi belajar dan lingkungan belajar kampus secara simultan (bersamasama) terhadap prestasi belajar.

\section{PENUTUP}

\section{Kesimpulan}

Berdasarkan dari hasil penelitian dan pembahasan, maka dapat disimpulkan bahwa:

a. Proses belajar mengajar berpengaruh positif dan signifikan terhadap prestasi belajar. Besar pengaruhnya $37,9 \%$ sedangkan sisanya $62,1 \%$ dipengaruhi oleh faktor-faktor lain. Persamaan regresi linier sederhana $\mathrm{Y}=14,886+0,639 \mathrm{X}_{1}$.

b. Motivasi belajar berpengaruh positif dan signifikan terhadap prestasi belajar. Besar pengaruhnya $37,8 \%$ sedangkan sisanya $62,2 \%$ dipengaruhi oleh faktor-faktor lain. Persamaan regresi linier sederhana $\mathrm{Y}=14,415+0,656 \mathrm{X}_{2}$. 
c. Lingkungan belajar kampus berpengaruh positif dan signifikan terhadap prestasi belajar. Besar pengaruhnya 33,3\% sedangkan sisanya 66,7\% dipengaruhi oleh faktorfaktor lain. Persamaan regresi linier sederhana $Y=13,693+0,604 X_{3}$.

d. Proses belajar mengajar, motivasi belajar dan lingkungan belajar kampus berpengaruh positif dan signifikan secara simultan (bersama-sama) terhadap prestasi belajar. Besar pengaruhnya 42,8\% sedangkan sisanya 57,2\% dipengaruhi oleh faktorfaktor lain. Persamaan regresi linier berganda $\mathrm{Y}=10,310+0,285 \mathrm{X}_{1}+0,178 \mathrm{X}_{2}+$ $0,283 \mathrm{X}_{3}$.

\section{Saran}

a. Mahasiswa disarankan untuk berupaya menumbuhkan rasa suka, tertarik dan memberikan perhatian yang besar dalam belajar bahkan tanpa disuruh serta berpartisipasi aktif dalam pembelajaran.

b. Bagi Mahasiswa dengan prestasi belajar yang kurang maksimal, disarankan agar lebih giat belajar dan lebih aktif mencari referansi terkait materi yang sedang dipelajari.

c. Dosen-dosen Program Studi S.1 Teknik Kimia Universitas Pamulang harus lebih meningkatkan strategi dan metode mengajar yang baik agar dapat meningkatkan pengetahuan dan kemampuan mahasiswa dalam memahami materi yang disampaikan.

d. Dosen-dosen Program Studi S.1 Teknik Kimia Universitas Pamulang disarankan untuk berupa menciptakan lingkungan belajar yang kondusif di dalam kelas selama proses belajar mengajar berlangsung dan memberikan hukuman berupa tugas khusus bagi mahasiswa yang membuat suasana kelas menjadi gaduh.

e. Dosen-dosen Program Studi S.1 Teknik Kimia Universitas Pamulang agar diberikan kesempatan yang banyak untuk mengikuti seminar ilmiah atau mengikuti pelatihan / training terutama terkait materi yang sesuai bidang / keahliannya.

f. Universitas Pamulang perlu memberikan beasiswa pendidikan kepada Dosen-dosen Program Studi S.1 Teknik Kimia Universitas Pamulang yang memiliki potensi untuk melanjutkan jenjang studinya.

g. Universitas Pamulang diharapkan untuk melengkapi peralatan labaratorium kimia di Program Studi S.1 Teknik Kimia Universitas Pamulang yang masih belum lengkap agar banyak mahasiswa Program Studi S.1 Teknik Kimia yang ingin melakukan penelitian di laboratorium kimia Universitas Pamulang.

h. Universitas Pamulang diharapkan menambah ketersediaan proyektor / infocus yang masih kurang untuk menunjang proses belajar mengajar.

i. Bagi peneliti selanjutnya, disarankan untuk melakukan penelitian lebih lanjut tentang faktor-faktor lain yang mempengaruhi prestasi belajar selain proses belajar mengajar, motivasi belajar dan ingkungan belajar kampus.

\section{DAFTAR PUSTAKA}

Ahmadi. 2004. Sosiologi Pendidikan. Jakarta: PT Rineka Cipta.

Akbar, I. R. (2018). Analisis Kebijakan Kepala Sekolah Dalam Upaya Meningkatkan Kompetensi Guru (Study Kasus Pada SMK Muhammadiyah Parung). Tesis. Universitas Pamulang . (2020). Pengaruh Kompensasi Dan Etos Kerja Terhadap Komitmen Organisasi Pada Pt. Central Buana Mandiri. Value: Jurnal Manajemen dan Akuntansi, 15(1), 73-80.

Arikunto, Suharsimi. 2010. Prosedur Penelitian Suatu Pendekatan Praktek. Jakarta: PT. Rineka Cipta.

Ariwibowo, Mustofa Setyo. Pengaruh Lingkungan Belajar terhadap Prestasi Belajar 
Departemen Pendidikan Nasional. 2008. Kamus Besar Bahasa Indonesia Pusat Bahasa. Edisi Keempat. Jakarta: PT. Gramedia Pustaka Utama.

Dessler, Gary. 2011. Manajemen Sumber Daya manusia. Jilid 1. Edisi 10. Jakarta: Indeks Djamarah, Syaiful Bakri. 2008. Psikologi Belajar. Jakarta : PT. Rineka Cipta.

Engkoswara. 2010. Administrasi Pendidikan. Bandung: Alfabeta.

Ghozali, Imam. 2011. Aplikasi Analisis Multivariate dengan Program IBM SPSS 19. Semarang: Badan Penerbit Universitas Diponegoro.

Ghozali. 2005. Analisis Multivariant dengan Program SPSS. Semarang: UNDIP

Griffin, R.W.2004. Manajemen. Edisi 7. Jakarta: Erlangga.

Hamalik, Oemar. 2007. Proses Belajar Mengajar. Cetakan II. Bandung: PT. Bumi Aksara. Handoko, Hani, Reksohadiprojo. 2008. Manajemen Personalia dan Sumber Daya Manusia. Yogyakarta: BPFE.

Hasibuan, Malayu S. P. 2008. “Manajemen Sumber Daya Manusia”. Jakarta: PT. Bumi Aksara

Hidayat, D., Prabowo, B., \& Anwar, S. (2020). Organizational Leadership and Conflict in Human Resource Management Review. Solid State Technology, 63(6), 1372-1381.

Jihad, Asep dan Haris, Abdul. 2009. Evaluasi Pembelajaran. Cetakan III. Yogyakarta: Multi Pressindo.

Riduwan, M.B.A. 2014. Metode dan Teknik Menyusun Tesis. Bandung: Alfabeta.

Rivai, Veithzal. 2004. Manajemen Sumber Daya Manusia Untuk Perusahaan. Jakarta: PT. Raja Grafindo Persada.

Siregar, Syofian. 2016. Satatistik Parametrik Untuk Penelitian Kuantitatif. Jakarta: Bumi Aksara.

Slameto. 2003. Belajar dan Faktor-Faktor yang Mempengaruhinya.. PT Rineka Cipta, Jakarta.

Sugihartono, dkk. 2007. Psikologi Pendidikan. Yogyakarta: UNY Press.

Sugiyono. 2006. MetodePenelitian Kuantitatif, Kualitatif dan R\&D. Bandung: Alfabeta.

Sujarweni, V Wiratna. 2014. Metodologi Penelitian. Yogyakarta: Pustaka Baru Press.

Sunarsi, D. (2016). Hubungan Pengendalian Diri dengan Prestasi Belajar. Penelitian. Fakultas Ekonomi Universitas Pamulang.

(2016, October). Pengaruh Minat, Motivasi Dan Kecerdasan Kognitif Terhadap Prestasi Belajar (Studi Kasus Pada Mahasiswa Program Studi S-1 Manajemen. Fakultas Ekonomi. Universitas Pamulang. Thn. Akademik 2015-2016). In Proceedings (Vol. 1, No. 1).

. (2017). Pengaruh Disiplin, Motivasi, Dan Kompetensi Terhadap Prestasi

Belajar (Studi Kasus Pada Mahasiswa Universitas Pamulang, Tangerang Selatan

Tahun Akademik 2016-2017). Jurnal Mandiri: Ilmu Pengetahuan, Seni, Dan Teknologi, 1(2), 207-226.

Suryabrata, Sumadi. 2011. Psikologi Pendidikan. Jakarta: PT. Raja Grafindo Persada.

Sutrisno, S., \& Sunarsi, D. (2019). The Effect of Work Motivation and Discipline on Employee Productivity at PT. Anugerah Agung in Jakarta. Jurnal Ad'ministrare, 6(2), 187-196.

Syah, Muhibbin. 2008. Psikologi Pendidikan dengan Pendekatan Baru. Bandung: PT. Remaja Rosdakarya.

Terry, George R. 2010. Teori Manajemen. Jakarta: Bina Aksara.

Tu'u, Tulus. 2004. Peran Disiplin Pada Perilaku dan Prestasi Siswa. Jakarta: PT. Gramedia Widiasarana. 